\title{
Novel Condensation System for Aqueous Solutions of Proteins. Facilitated Permeation of Proteins through a Porous Membrane Prepared from a Block Copolymer Consisting of Hydrophilic Polyamide and Polyoxyethylene Segments
}

\author{
Kazuhiko Hashimoto, Hiroshi Sumitomo, and Hiroo YAmamori
}

Faculty of Agriculture, Nagoya University,

Furo-cho, Chikusa-ku, Nagoya 464, Japan

(Received February 6, 1987)

\begin{abstract}
A new porous membrane was prepared from a block copolymer consisting of hydrophilic polyamide as outer segments and polyoxyethylene as an inner segment by casting the solution of the mixture of the block copolymer with polyoxyethylene glycol and drying up at room temperature, followed by immersing and rinsing in water. In the solute rejection test for some proteins, the concentration of the permeate was found to be much higher than that in the feed. Such peculiar condensation was much dependent not only upon the casting conditions for the porous membrane, but also upon permeation conditions such as the pressure difference, mechanical stirring, and the initial concentration of protein solutions. The present transport system is presumed to result from the delicate combination of the rapid adsorption of proteins onto the porous membrane and their transport driven by the lower pressure.

KEY WORDS Condensation / Protein / Facilitated Permeation / Porous

Membrane / Block Copolymer / Polyamide / Polyoxyethylene /
\end{abstract}

The properties and functions of copolymers are well known to depend not only upon the primary structures such as the composition and the sequence distribution, but also upon the higher-order structures such as the phaseseparation, crystallinity, and so on. Their fine control is a main subject for the design of functional polymer materials. ${ }^{1-3}$ Phase separation is also one of the important precesses during the formation of the porous polymer membrane. ${ }^{4}$

Recently a new block copolymer (1) composed of polyamide as outer segments and polyoxyethylene (abbreviated as POE) as an inner segment was prepared by the anionic polymerization of a bicyclic oxalactam, 8-oxa6-azabicyclo[3.2.1]octan-7-one (BOL, 2), by the use of an isocyanate-terminated polyoxyethylene as an activator. ${ }^{5-7}$ The hydrophilic dense membrane obtained easily from the resulting block copolymer exhibited high water permeability. ${ }^{5-7}$ Such high hydraulic permeability can be presumed to result mainly from the hygroscopicity of the inner flexible POE segment.

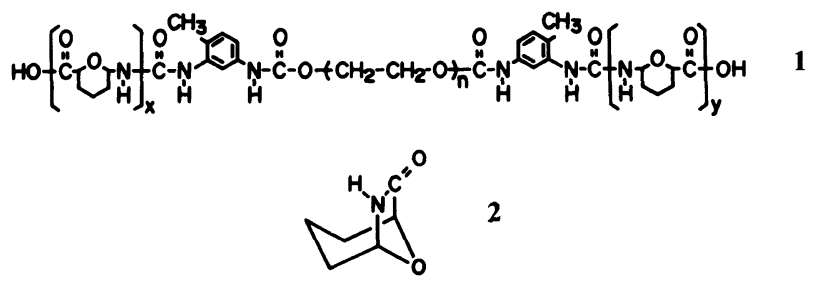


The present article describes the preparation of the block copolymer membrane having porous POE domains and its application to a novel condensation system for an aqueous solution of proteins.

\section{EXPERIMENTAL}

The procedure for the preparation of the block copolymer (1) has been described in the previous articles. ${ }^{5-7}$ The mixtures of 1 and polyoxyethylene glycol (POE-OH, $\bar{M}_{n} 19,000$ ) in various ratios at a concentration of $3 \%$ in chloroform-methanol (10:1 wt) mixed solvent were cast on glass plates and dried up at room temperature, respectively. After the plate was repeatedly immersed and rinsed in water at room temperature for several days, the resulting porous membrane was peeled from the plate. The eluted POE-OH was recovered by the evaporation of water from the solution and dried in vacuo for weighing.

The permeation rate of water through the porous membrane was measured at $25^{\circ} \mathrm{C}$ under a pressure difference of $1-3 \mathrm{~kg} \mathrm{~cm}^{-2}$ by using a commercial ultrafiltration cell, of which the effective membrane area was $13.9 \mathrm{~cm}^{2}$. $^{8-10}$

The permeation test of the aqueous so- lutions of various proteins through the membranes was conducted using the same ultrafiltration cell, which was filled with $50 \mathrm{ml}$ of the solutions of various concentrations, at $25^{\circ} \mathrm{C}$ under a pressure difference of $1-3 \mathrm{~kg} \mathrm{~cm}^{-2}$ with or without mechanical stirring. The solute concentration in the permeate was determined by UV spectrometry. The amount of proteins adsorbed in the membrane was estimated from the decrease of the concentration of a certain amount of the aqueous solution, in which a certain size of the membrane was dipped. All proteins used in the permeation test were obtained from Sigma Chemicals, Inc.

\section{RESULTS AND DISCUSSION}

After casting and drying the polymer solution on the plate, POE-OH was eluted by immersion and rinsing of the plate in water and almost quantitatively recovered from the aqueous phase. The resulting block copolymer membrane could be peeled from the plate unless the amount of POE-OH was larger than that of $\mathbf{1}$ in the casting solution. However the membrane was broken on the peeling, when POE-OH was twice the weight of 1 in the casting solution, even when the amount of 1 for the casting increased.

Table I. Characteristics of various porous membranes prepared from a black copolymer composed of polyamide and polyoxyethylene segments

\begin{tabular}{|c|c|c|c|c|c|c|c|}
\hline \multirow{2}{*}{$\begin{array}{c}\text { Membrane } \\
\text { No. }\end{array}$} & \multirow{2}{*}{$\begin{array}{l}\text { Weight ratio } \\
\text { of POE-OH to } \\
\text { copolymer } \\
\text { on casting }\end{array}$} & \multirow{2}{*}{$\begin{array}{l}\text { Degree of } \\
\text { hydration }^{b}\end{array}$} & \multirow{2}{*}{$\frac{\text { Thickness }^{\mathrm{c}}}{\mu \mathrm{m}}$} & \multirow{2}{*}{$\begin{array}{c}\begin{array}{c}\text { Water } \\
\text { flux }\end{array} \\
1 \mathrm{~m}^{-2} \cdot \mathrm{h}\end{array}$} & \multirow{2}{*}{$\frac{K_{\mathrm{w}} \times 10^{9}}{\mathrm{~mol} \mathrm{~cm} \mathrm{~cm}^{-1} \cdot \mathrm{s} \cdot \mathrm{atm}}$} & \multirow{2}{*}{$\frac{[\mathrm{c}]_{\mathrm{m}}^{\mathrm{d}, \mathrm{e}}}{[\mathrm{c}]_{0}}$} & \multirow{2}{*}{$\begin{array}{c}\begin{array}{c}\text { Adsorbed } \\
\text { myoglobin }\end{array} \\
\mathrm{mgg}^{-1} \text { dry polymer }\end{array}$} \\
\hline & & & & & & & \\
\hline 4 & 0 & 0.58 & 120 & 0.19 & 1.68 & 0.11 & 0.1 \\
\hline 10 & 0.1 & 0.66 & 170 & 0.29 & 3.86 & 0.09 & - \\
\hline 21 & 0.3 & 0.74 & 87 & 1.53 & 10.3 & 5.7 & 15 \\
\hline 11 & 0.5 & 0.69 & 170 & 0.39 & 5.25 & 4.6 & - \\
\hline 9 & 1.0 & 0.76 & 220 & 2.15 & 36.1 & 2.1 & 4.3 \\
\hline
\end{tabular}

a Block copolymer: weight fraction of polyamide segments, 0.82 ; molecular weight of polyoxyethylene segment, 19,000. POE-OH: molecular weight, 19,000.

b Volume fraction of water in membrane.

c In wet state.

d Area, $13.9 \mathrm{~cm}^{2}$; temperature, $25^{\circ} \mathrm{C}$; pressure, $2 \mathrm{~kg} \mathrm{~cm}^{-2}$.

e Feed, $50 \mathrm{ml}$ of $0.025-0.03 \mathrm{wt} \%$ solution; mechanical stirring, $450 \mathrm{rpm}$. 
From the above-mentioned results the obtained porous membrane may be speculated to have a kind of phase-separated structure containing polyamide domains as a matrix and the POE domains as spheres or rods similarly to the dense membrane. ${ }^{7}$ In addition, the POE domains in the porous membrane must be wider but coarser than those in the dense ones. When the amount of POE-OH was twice that of $\mathbf{1}$ in the casting solution, the porous matrix composed of the polyoxyethylene segment and POE-OH must have been formed in the membrane on the plate before the peeling, which may be a main reason that the corresponding membrane broke on the peeling from the plate after immersing.

As tabulated in Table $\mathrm{I}$, the degrees of hydration, water flux, and hydraulic permeability $\left(K_{\mathrm{w}}\right)$ for the porous membranes were higher than those for the dense membrane, respectively. These values seem to become higher with the increase of the amount of $\mathrm{POE}-\mathrm{OH}$ in the casting solution but not those of the membrane No. 21 in Table I. This exception suggests that any uncontrollable minor difference of the casting conditions has an appreciable influence on the shape and/or size of the domains in the phase-separated structure formed in the blend membrane.

As shown in Figure 1, the $0.025-0.03 \mathrm{wt}^{\mathrm{o}} \%$ aqueous solution of myoglobin was fed into the cell and permeated through block copolymer membranes at $25^{\circ} \mathrm{C}$ under a pressure difference of $2 \mathrm{~kg} \mathrm{~cm}^{-2}$ with mechanical stirring. The concentrations of the permeates ([c]) for the porous membranes (No. 21 and 9 of which properties are summarized in Table I) were found to be unusually higher than that in the feed $\left([c]_{0}\right)$. Thus the percents of the solute rejection for the membranes corresponded to about $-560 \%$ and $-130 \%$ in minimum, respectively, while the dense membrane (No. 4) rejected myoglobin molecules by about $90 \%$ in a similar manner as conventional membranes for ultrafiltration. During the permeation through the porous membrane, the concen-

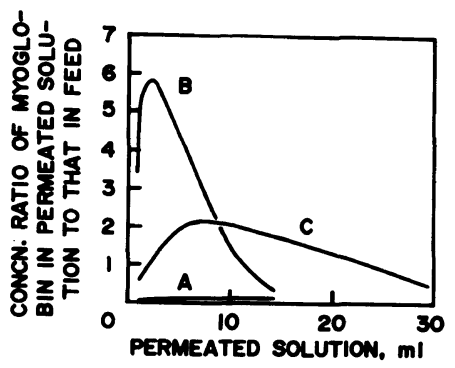

Figure 1. Permeation of an aqueous solution of myoglobin through various block copolymer membranes at $25^{\circ} \mathrm{C}$ under $2 \mathrm{~kg} \mathrm{~cm}^{-2}$ (feed, $50 \mathrm{ml}$ of $0.025-0.03 \mathrm{wt} \%$ solution; mechanical stirring, $450 \mathrm{rpm})$. Membrane area, $13.9 \mathrm{~cm}^{2}$. A, membrane No. 4 (dense membrane); B, No. 21; C, No. 9.

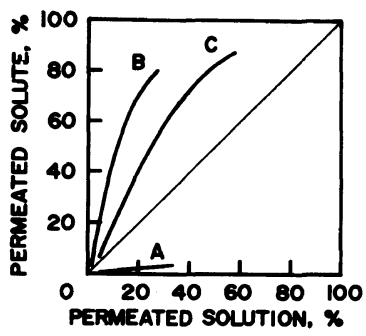

Figure 2. Relationship between amounts of solute and solution permeated through porous block copolymer membranes (experimental conditions are the same as in Figure 1). A, membrane No. 4; B, No. 21; C, No. 9.

tration ratio expressed by the value of $[\mathrm{c}] /[\mathrm{c}]_{0}$ increased progressively and revealed a maximum followed by a gradual decrease.

The apparently similar condensation is known to be rarely observed in the ultrafiltration test through the commercial membrane without mechanical stirring. However it should be accompanied by drastic decrease of the flux due to concentration polarization. ${ }^{11,12}$ In the present system, the flux of the permeation was not lower than the water flux for each membrane.

From the relationship between the amounts of solute and solution permeated through the porous membrane (No. 21) as shown in Figure 2 , about $70 \%$ of myoglobin molecules in the feed was found to have permeated during the permeation of one fifth of the solution. In usual ultrafiltration, the permeation of a great amount of water accompanied by the rejection 
of the solute results in the condensation of the solution. In the present system the condensation was accomplished by the facilitated permeation of the solute. Therefore it can be regarded as a kind of energy-saving condensation system for aqueous solutions.

The apparunt maximum concentration ratio $\left([\mathrm{c}]_{\mathrm{m}} /[\mathrm{c}]_{0}\right)$ was used here as a measure for such condensation of the protein solution by its facilitated permeation, although the real condensation ratio in the present system should be higher than it because of the decrease of the feed concentration during the permeation. The values on the permeation of myoglobin for various membranes are summarized in Table I. The membranes prepared from the mixtures of POE- $\mathrm{OH}$ with 1 at a weight ratio of $0.3-0.5$ seem to be useful for the present purpose.

Table I shows also that the porous membrane can adsorb a great amount of myoglobin, which may be necessary for the present condensation.

Nakayama et $a .^{13}$ reported that the ethylene-vinyl alcohol copolymer membrane rejected lysozyme by about $70 \%$ but permeated cytochrome $c$ singularly, which corresponded to $-20--120 \%$ of the apparent rejection, in spite of almost the same molecular weight of the latter as the former one. Therefore the permeability of various proteins through the present porous block copolymer membrane (No. 9) was examined and is listed in Table II together with the ability of their adsorption. Cytochrome $c$ and lysozyme, of which molecular weights were not so different from that of myoglobin, were found to be adsorbed on the membrane, but $\alpha$-chymotrypsinogen and bovine serum albumin were little adsorbed. Among them cytochrome $c$ could permeate with its simultaneous condensation, as well as myoglobin. From the abovementioned observation, the permeation of proteins accompanied by their condensation can be inferred to need not only rapid adsorption on the porous membrane but also other factors, such as high diffusion and rapid
Table II. Permeation of various proteins through the porous block copolymer membrane ${ }^{a}$

\begin{tabular}{|c|c|c|c|c|}
\hline \multicolumn{2}{|l|}{ Protein } & \multirow{2}{*}{$\frac{[c]_{0}}{w t^{\%} \%}$} & \multirow{2}{*}{$\frac{[\mathrm{c}]_{\mathrm{m}}{ }^{\mathrm{b}}}{[\mathrm{c}]_{0}}$} & \multirow{2}{*}{$\begin{array}{c}\begin{array}{c}\text { Adsorbed } \\
\text { protein }\end{array} \\
\mathrm{mgg}^{-1} \text { dry } \\
\text { polymer }\end{array}$} \\
\hline & $\bar{M}_{n}$ & & & \\
\hline Cytochrome $c$ & 13000 & 0.02 & 4.1 & 14.9 \\
\hline Lysozyme & 14500 & 0.08 & 0.90 & 9.2 \\
\hline Myoglobin & 17800 & 0.03 & 2.1 & 4.3 \\
\hline$\alpha$-Chymotrypsinogen & 24500 & 0.15 & 0.86 & $\sim 0$ \\
\hline Bovine serum albumin & 65000 & 0.10 & 0.16 & $\sim 0$ \\
\hline
\end{tabular}

a Membrane No. 9 in Table I.

b Feed, $50 \mathrm{ml}$; area, $13.9 \mathrm{~cm}^{2}$; temperature, $25^{\circ} \mathrm{C}$; pressure, $2 \mathrm{~kg} \mathrm{~cm}^{-2}$; mechanical stirring, $450 \mathrm{rpm}$.

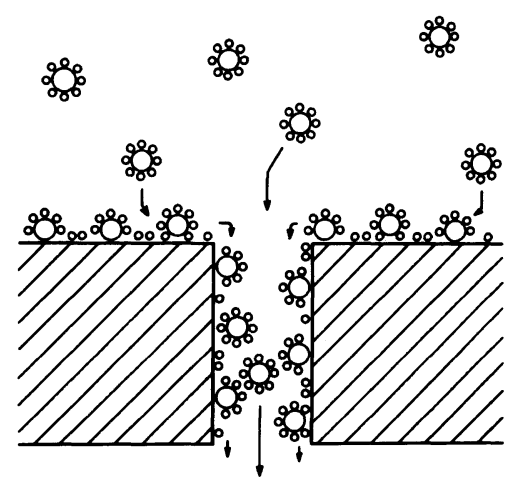

Figure 3. Schematic representation of facilitated permeation of proteins in aqueous solutions through porous membrane. $O$, protein molecule; $O$, hydrating water molecule.

desorption.

By reference to Ferry's filtration models, ${ }^{11,12,14}$ the mechanism for such unusual condensation of proteins through the present porous membrane is speculated below and shown schematically in Figure 3. Taking into account that the present membrane should have a phase-separated structure containing porous POE domains, the adsorbed protein should exist not only on the surface of the membrane but also on the inner wall of the pores, which may be covered by the hydrogel composed of the POE segment. The fed protein solution must pass, of course, through the 
pores under a driving force of low pressure. The high concentration phase of the protein formed along the membrane surface and the inner wall of the pores is also presumed to be pushed out by the pressure. Consequently it may happen that the protein concentration in the permeate is much higher than that in the feed.

In the case of the dense membrane (No. 4) the contribution of the inner wall of the pores to the overall area of the membrane surface can be speculated to be lower than in the case of porous ones, which must decrease the amount of protein adsorbed on the membrane and the relative permeation rate of the protein to that of water as shown in Table $I$ and Figures 1 and 2.

If the above-proposed hypothesis is valid, the extent of the condensation of proteins should depend upon several operating conditions such as the mechanical stirring of the fed solution, the operating pressure difference, the concentration of proteins, and so on.

As shown in Figure 4, the mechanical stirring of the fed aqueous solution of myoglobin was effective for its facilitated permeation, but such condensation was not observed during permeation without mechanical stirring. The saturated value of $[c]_{\mathrm{m}} /[\mathrm{c}]_{0}$ at a high rate of mechanical stirring (see Figure 5) may correspond to the saturation of the amount of myoglobin adsorbed on the membrane. But the amount of myoglobin adsorbed during the permeation has not been determined yet.

The operating pressure increased the flux of the permeate but the most effective condensation of myoglobin was realized at a pressure difference of $2 \mathrm{~kg} \mathrm{~cm}^{-2}$ as shown in Figure 6. At a pressure difference of $3 \mathrm{~kg} \mathrm{~cm}^{-2}$, the adsorption of myoglobin onto the membrane can be presumed to be apt to be delayed by the high flux of the permeate. On the other hand the desorption of myoglobin from the membrane may be relatively hard at a pressure difference of $1 \mathrm{~kg} \mathrm{~cm}^{-2}$ because of the low flux.

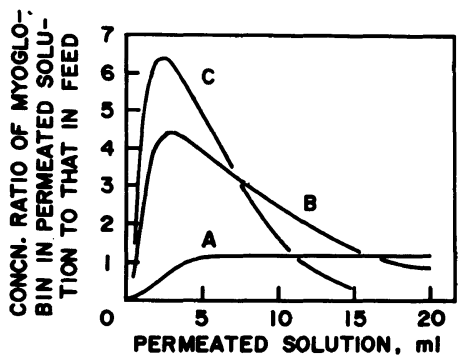

Figure 4. Permeation of an aqueous solution of myoglobin through the porous block copolymer membrane at $25^{\circ} \mathrm{C}$ under $2 \mathrm{~kg} \mathrm{~cm}^{-2}$. Membrane No. 21 ; feed, $50 \mathrm{ml}$ of $0.01 \mathrm{wt} \%$ solution. Mechanical stirring of feed solution: A, 0; B, 150; C, $450 \mathrm{rpm}$.

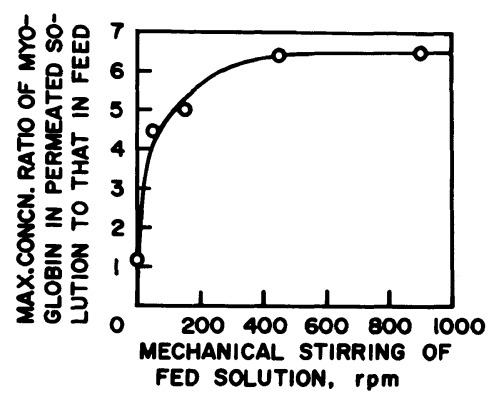

Figure 5. Effect of mechanical stirring upon permeation of aqueous solution of myoglobin through the porous block copolymer membrane. Membrane No. 21 (experimental conditions are the same as in Figure 4).

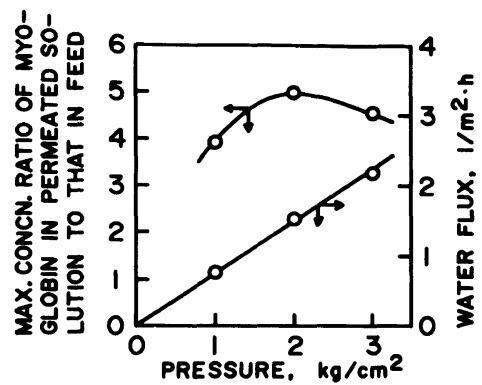

Figure 6. Effects of operating pressure difference upon permeation of the aqueous solution of myoglobin through the porous block copolymer membrane at $25^{\circ} \mathrm{C}$. Membrane No. 21 ; feed, $50 \mathrm{ml}$ of $0.01 \mathrm{wt} \%$ solution; mechanical stirring, $150 \mathrm{rpm}$.

The permeation of myoglobin accompanied by its condensation was also remarkably influenced by the initial concentration of the fed solution (Figures 7 and 8 ). The highest value of 


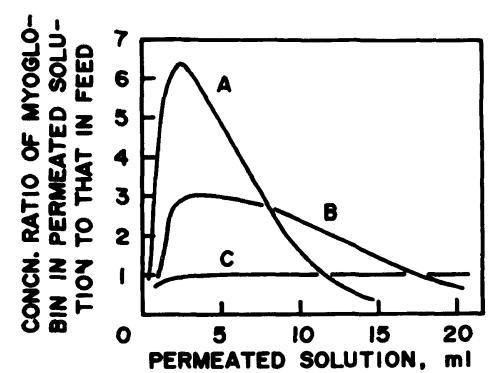

Figure 7. Permeation of various concentrations of myoglobin in water through the porous block copolymer membrane at $25^{\circ} \mathrm{C}$ under $2 \mathrm{~kg} \mathrm{~cm}^{-2}$. Membrane No. 21 ; mechanical stirring, $450 \mathrm{rpm}$. Concentration of myoglobin in the feed: A, $0.01 ; \mathrm{B}, 0.05 ; \mathrm{C}, 0.2 \mathrm{wt} \%$.

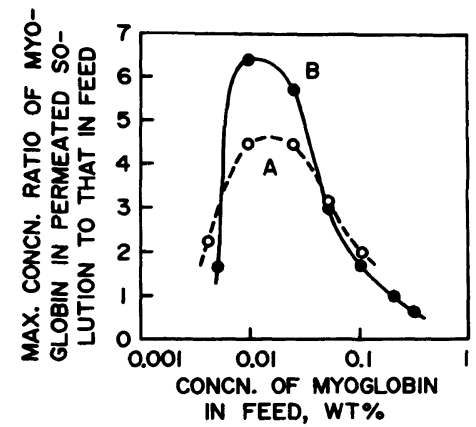

Figure 8. Effect of concentration of myoglobin in fed aqueous solution upon its permeation through the porous block copolymer membrane at $25^{\circ} \mathrm{C}$ under $2 \mathrm{~kg} \mathrm{~cm}^{-2}$. Membrane No. 21. Mechanical stirring: A, 50; B, $450 \mathrm{rpm}$.

$[c]_{m} /[c]_{0}$ was observed in the permeation test using the myoglobin solution, of which concentration was in the range from 0.01 to $0.03 \mathrm{wt} \%$. On the permeation test for the $0.2 \mathrm{wt} \%$ solution of myoglobin, however, the concentration of the permeate was almost the same as that in the feed and even the rejection of myoglobin was observed on the run for the $0.3 \mathrm{wt} \%$ fed solution just like usual ultrafiltration. These results can also be explained reasonably, if it is assumed that there is a limit to the amount of myoglobin adsorbed on the membrane, that is, a saturated value of the concentration of the permeate. On the contrary, the value of $[\mathrm{c}]_{\mathrm{m}} /[\mathrm{c}]_{0}$ decreased in the run for the $0.005 \mathrm{wt} \%$ fed solution. The desorption

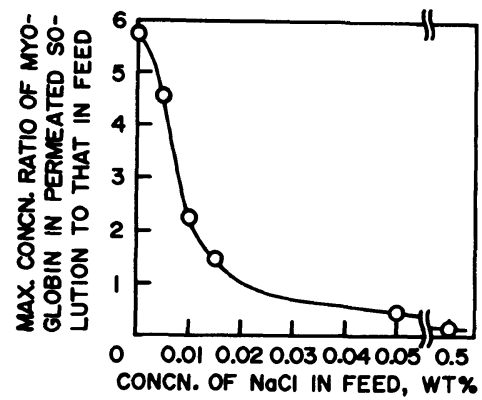

Figure 9. Permeation of an aqueous solution of myoglobin in the presence of sodium chloride through the porous block copolymer membrane at $25^{\circ} \mathrm{C}$ under $2 \mathrm{~kg} \mathrm{~cm}^{-2}$ (feed, $50 \mathrm{ml}$ of $0.025 \mathrm{wt}_{\%}^{\circ}$ solution of myoglobin; mechanical stirring, $450 \mathrm{rpm}$ ). Membrane No. 21.

of myoglobin adsorbed on the membrane may be relatively hard in its low concentration solution.

Now the nature of the adsorption of proteins on the membrane should be discussed. Essentially, proteins are hydrated in the aqueous solution, which has been investigated by several workers. ${ }^{15,16}$ As described before, the POE segment in the block copolymer must also have fairly strong interactions with water molecules to form a kind of hydrogel phase Therefore, the interaction between the protein and the POE segment can be presumed not to be so strong. Nevertheless, any significant interaction must exist between them.

As shown in Figure 9, the addition of the $0.01 \mathrm{wt} \%$ of sodium chloride into the aqueous solution of myoglobin brought about a drastic decrease of the extent of condensation of myoglobin. Even the rejection of myoglobin was observed in the presence of $0.05 \mathrm{wt} \%$ or more or the electrolyte. There may be some electrostatic interaction between myoglocin and the membrane, which should be weakened by the addition of the electrolyte. A similar effect of the electrolyte has also been reported in the facilitated permeation of cytochrome $c$ through the ethylene-vinyl alcohol copolymer membrane. ${ }^{13}$ It may also be noted that myoglobin and cytochrome $c$, which were 
condensed by their permeation through the present membrane, are both heme proteins having ferrous porphyrin complexes.

In summary, the new porous hydrophilic membrane was prepared from the block copolymer having polyamide and POE segments, and a protein solute in an aqueous solution was found to permeate preferentially through the membrane under a pressure difference of $2 \mathrm{~kg} \mathrm{~cm}^{-2}$ with mechanical stirring. Such an unusual transport system is presumed to result from the delicate combination of the rapid but not so strong adsorption of proteins onto the porous membrane and their permeation driven by the lower pressure.

\section{REFERENCES}

1. A. Noshay and J. E. McGrath, "Block Copolymers," Academic Press, New York, 1977.

2. J. A. Manson and L. H. Sperling, "Polymer Blends and Composites," Plenum Press, New York, 1976.

3. The Society of Polymer Science, Japan, Ed., "Polymer Alloys," Tokyo Kagaku Dojin Co., Ltd., Tokyo, 1981.
4. K. Kamide, S. Manabe, T. Matsui, T. Sakamoto, and S. Kajita, Kobunshi Ronbunshu, 34, 205 (1977).

5. K. Hashimoto, H. Sumitomo, and H. Yamamori, Polym. J., 17, 679 (1985).

6. K. Hashimoto and H. Sumitomo, Makromol. Chem., Suppl., 12, 39 (1985).

7. K. Hashimoto, H. Sumitomo, and H. Yamamori, Polym, J., 19, 249 (1987).

8. H. Sumitomo, K. Hashimoto, and T. Ohyama, Polym. Bull., 1, 133 (1978).

9. K. Hashimoto and H. Sumitomo, Macromolecules, 13, 786 (1980).

10. M. Kawaguchi, T. Taniguchi, K. Tochigi, and A. Takizawa, J. Appl. Polym. Sci., 19, 2515 (1975).

11. R. E. Kesting, "Synthtic Polymeric Membranes," Second Ed., John Wiley \& Sons, New York, 1985, p 60.

12. H. Ohya, "Gyakushintoh-ho Gengairoka-ho I Riron (Reverse Osmosis Ultrafiltration I Theory)," SaiwaiShoboh, Tokyo, 1976, pp 76 and 275.

13. M. Nakayama and S. Yamamoto, Preprints of the Fourth Annual Meeting of the Membrane Society of Japan, 1982, p 25.

14. J. Ferry, Chem. Rev., 18, 373 (1936).

15. I. D. Kuntz and W. Kangmann, Adv. Protein Chem., 28, 239 (1974).

16. K. Gekko and H. Noguchi, J. Phys. Chem., 83, 2706 (1979). 